\title{
Karbonoan oinarritutako nanomaterialen eta mikro eta nanoplastikoen eragina kutsatzaile organiko iraunkorren garraiatzaile gisa organismo itsastarretan
}

\author{
(Impact of carbon based nanomaterials and micro and nanoplastics \\ as carriers of persistent organic pollutants in marine organisms)
}

\author{
Nagore González-Soto, Eider Bilbao, Miren P. Cajaraville*
}

Zelulen Biologia Ingurumen Toxikologian (ZBIT) ikerketa taldea, Zoologia eta Animalia Zelulen Biologia Saila, Zientzia eta Teknologia Fakultatea eta Plentziako Itsas Estazioa (PiE), Euskal Herriko Unibertsitatea UPV/EHU, Leioa, Bizkaia.

\begin{abstract}
LABURPENA: Industriaren eta teknologiaren garapenak ezaugarri fisiko-kimiko bereziak dituzten material berriak sortzea eragin du, eta, horien artean, nanomaterialak gero eta ugariagoak dira. Nanomaterialak gutxienez nanoeskaladun $(<100 \mathrm{~nm})$ dimentsio bat duten materialak dira rien artean, nanomaterialak gero eta ugariagoak dira. Nanomaterialak gutxienez nanoeskaladun $(<100 \mathrm{~nm})$ dimentsio bat duten materialak dira.
Gaur egun, Europako legedian ez dago nanomaterialentzako araudi berezirik, nahiz eta, haien homologo makroskopikoekin alderatuta, ezaugarri fisiko-kimiko ezberdinak agertu. Mikroplastikoak $5 \mathrm{~mm}$ baino txikiagoak diren plastikozko materialak dira eta nanoplastikoak, $100 \mathrm{~nm}$ baino txikiagoak direnak. Plastiko makroskopikoen eraginak zabal ikertu diren arren, mikroplastiko eta nanoplastikoen inguruko hausnarketa duela gutxi hasi da egiten. Nanomaterialak, mikro eta nanoplastikoak, iturri desberdinetatik iristen dira itsasora eta, beraz, itsas organismoetan eragin ditzaketen kalteen inguruko kezka zabaldu da. Gainera, nanomaterialek, mikroplastikoek eta nanoplastikoek duten azalera/bolumen erlazio handia eta hidrofobizitatea dela eta, arrisku gehigarri bat dute: kutsatzaile organiko iraunkorren garraiatzaile gisa joka dezakete itsasoan. Hau da, nanomaterialek, mikroplastikoek eta nanoplastikoek, itsasoan dauden kutsatzaile organiko iraunkorrak adsorbatu ditzakete eta haien eskuragarritasuna emendatu organismo itsastarrentzat. Lan honen xedea da karbonoan oinarritutako nanomaterialek eta mikro eta nanoplastikoek hainbat espezie itsastarretan eragindako kalte fisiologikoak zein zelula eta molekula mailako kalteak berrikustea. Kalte horiek, kutsatzaile organiko iraunkordun karbonoan oinarritutako nanomaterialek, mikro eta nanoplastikoek, eragindako kalteekin alderatu ere egin nahi dira. Adibidez, mikroplastikodun mikroalgekin elikatutako muskuiluek mikroplastikoak agertu dituzte urdailaren argian, digestio epitelioan eta ehun konektiboan, eta bentzo(a)pirenoa moduko kutsatzaile organiko iraunkorra adsorbatuta duten mikroplastikodun mikroalgekin elikatutako muskuiluek bentzo(a)pirenoa metatzen dute ehunetan. Mikroplastikoek bakarrik zein kutsatzaile organikodun mikroplastikoek immunotoxizitatea, kalte fisiologikoak eta DNA mailako kalteak eragiten dizkiete muskuiluei. Hortaz, ingurune konplexu batean, hala nola itsasoan, kutsatzaileak ez direnez modu isolatuan agertzen, ezagutza hori kontuan hartu beharko litzateke, itsas ekosistemen osasuna eta segurtasuna bermatzeko.

HITZ GAKOAK: Karbonoan oinarritutako nanomaterialak, mikro eta nanoplastikoak, kutsatzaile organiko iraunkorrak, «Troiako zaldia» delako fenomenoa, efektu biologikoak, muskuiluak.
\end{abstract}

ABSTRACT: The development of industry and technology has led to the synthesis of new materials with unique physico-chemical properties, among them, nanomaterials are becoming abundant. Nanomaterials are materials with at least one dimension at the nanoscale $(<100 \mathrm{~nm})$. At present, there is no specific regulation for nanomaterials in European law, although their physico-chemical properties are different in comparison to their bulk counterparts. Microplastics are plastic materials smaller than $5 \mathrm{~mm}$ while nanoplastics are smaller than $100 \mathrm{~nm}$. Whilst the impacts of macroplastics are well studied, it was only in recent years that interest developed in understanding the effects of micro and nanoplastics. Nanomaterials, micro and nanoplastics originate from different sources and reach the sea. As a result, their effects on marine biota represent a major concern. Due to the high surface/volume ratio and hydrophobicity of nanomaterials, micro and nanoplastics, they pose an additional risk: they can adsorb persistent organic pollutants and act as their carriers, increasing bioavailability of these compounds to marine organisms. The purpose of this work is to review the potential effects caused by carbon based nanomaterials, micro and nanoplastics in different marine organisms at molecular, cellular and physiological levels and to compare these effects to those caused by nanomaterials, micro and nanoplastics with adsorbed persistent organic pollutants. For example, after feeding mussels with a diet containing microplastics, these have been found in gut lumen, digestive epithelium and connective tissue and in mussels fed with microplastics with adsorbed benzo(a)pyrene, benzo(a)pyrene, was accumulated in mussel tissues. Microplastics alone and with adsorbed persistent organic pollutants produce inmunotoxic, genotoxic and deleterious physiological effects. Thus, since pollutans do not appear isolated in the complex marine environment, this knowledge should be taken into account to ensure the health and safety of marine ecosystems.

KEYWORDS: Carbon based nanomaterials, micro and nanoplastics, persistent organic pollutants, «Trojan horse» phenomenon, biological effects, mussels.

* Harremanetan jartzeko / Corresponding author: Miren P. Cajaraville, ZBIT ikerketa taldea, Zoologia eta Animalia Zelulen Biologia Saila, Zientzia eta Teknologia Fakultatea, Euskal Herriko Unibertsitatea UPV/EHU, Sarriena s/n, E-48940 Leioa, Bizkaia. Euskal Herria. - mirenp.cajaraville@ehu.eus - https://orcid.org/0000-0001-6527-6137.

Nola aipatu / How to cite: González-Soto, Nagore; Bilbao, Eider; Cajaraville, Miren P. (2020). "Karbonoan oinarritutako nanomaterialen eta mikro eta nanoplastikoen eragina kutsatzaile organiko iraunkorren garraiatzaile gisa organismo itsastarretan"; Ekaia, ale berezia 2020, 275-298. (https://doi.org/10.1387/ekaia.21085).

Jasoa: 12 iraila, 2019; Onartua: 3 martxoa, 2020

ISSN 0214-9001 - elSSN 2444-3255 / (c) 2020 UPV/EHU

cc)(-) Obra hau Creative Commons Atribución 4.0 Internacional-en

lizentziapean dago 


\section{SARRERA: NANOMATERIALAK}

Industriaren eta teknologiaren garapenak ezaugarri fisiko-kimiko bereziak dituzten material berriak sortzea eragin du. Horien artean, nanomaterialak (NMak) gero eta ugariagoak dira gure egunerokotasunean (medikuntza, kosmetika, energia berriztagarriak, elektronika, erremediazioa...). Gaur egun, nanomaterialak 3.000 produktu baino gehiagotan topa ditzakegu (http://nanodb.dk/en/search-database/).

NMak nanoeskalan $(<100 \mathrm{~nm})$ gutxienez dimentsio bat duten materialak dira [1]. Nanoeskalan duten dimentsio kopuruaren arabera NMak zenbait kategoriatan banatu daitezke: 0D (esferikoak, adibidez: fulereno eta nanopartikulak), 1D (hodiak eta hariak, adibidez: karbono-nanohodiak eta urrezko nanohariak), 2D (xaflak eta plakak, adibidez: grafenoa eta grafeno oxidoa) eta 3D (edozein 3Dko egitura, adibidez: urrezko nanokuboak eta DNA tetrahedronak) $[2,3]$. Nanomaterialen ezaugarri fisiko-kimikoek (azalera, forma, materiala, tamaina, egonkortasuna, talde funtzionalak, karga, hidrofobizitatea, elkartzeko joera...) haien aplikazioak zein molekula biologikoekiko elkarrekintzak baldintzatzen dituzte (1. irudia).

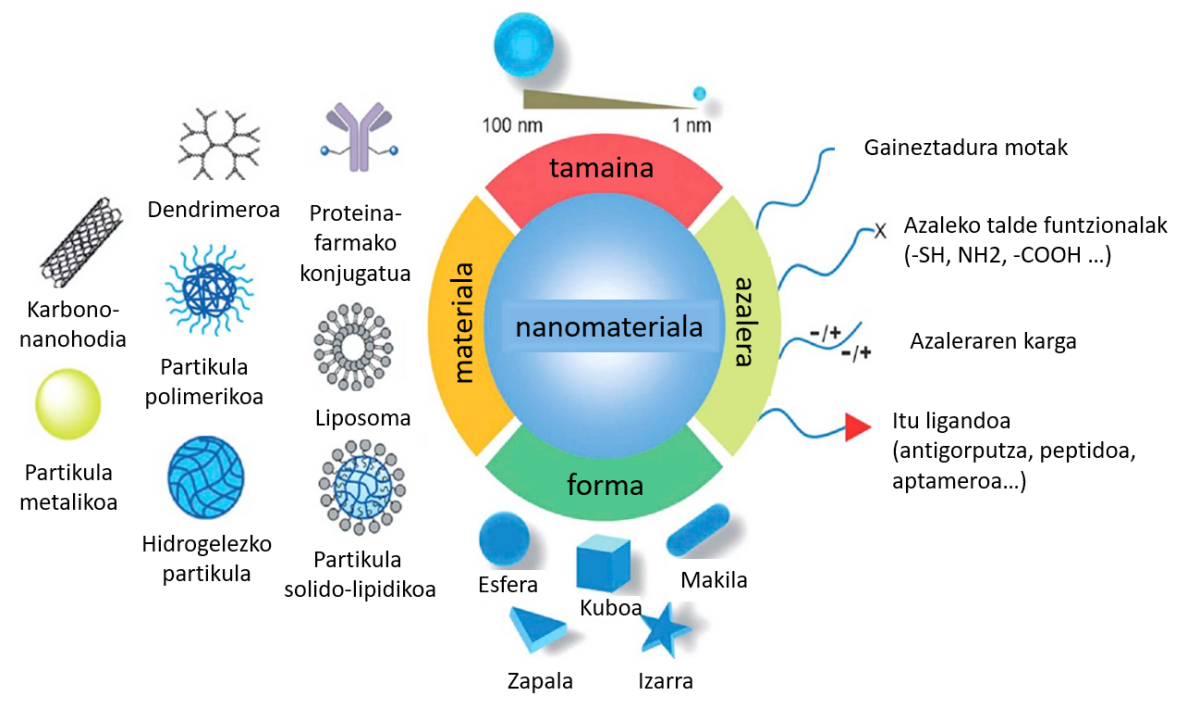

1. irudia. Nanomaterialen ezaugarri nagusiak (Heinz et al., 2017-tik moldatua) [4].

NMek duten azalera/bolumen erlazio handiagatik ezaugarri bereizgarriak dituzte beren homologo makroskopikoekin alderatuta [1]. Ezaugarri horiek direla eta, ingurunera askatzen direnean organismoetan sor ditzake- 
Karbonoan oinarritutako nanomaterialen eta mikro eta nanoplastikoen eragina

kutsatzaile organiko iraunkorren garraiatzaile gisa organismo itsastarretan

ten kalteen inguruko kezka zabaldu da aspaldian [5]. Hala ere, Europako legedian ez dago NMentzako araudi berezirik, eta «sustantzia» gisa sailkatzen dira beren homologo makroskopikoekin batera.

\section{KARBONOAN OINARRITUTAKO NANOMATERIALAK}

NMen artean, karbonoaren alotropoak ezagunak dira era askotako egitura eta ezaugarriak dituztelako. Karbonoan oinarritutako NM horiek $\mathrm{sp}^{2}$ karbono atomoz eratuta eta $\mathrm{OD}$ eta 3D bitartean daude [6-9]. Karbonoan oinarritutako NMen artean aipagarriak dira nanodiamanteak, karbono-nanohodiak, karbono beltza eta grafenoa [10-13].

Karbonoan oinarritutako NMen ekoizpena bortizki emendatu da azken urteotan haien ezaugarri elektromagnetiko, optiko, katalitiko, mekaniko, termiko eta farmakokinetikoengatik [14]. Arestian aipatutako «The nanodatabase» datu-basearen arabera [15], gaur egun karbonoan oinarritutako NMak topa ditzakegu kosmetika eta higiene pertsonalerako produktuetan, arropetan, garbiketa sistemetan, elikagaiekin erlazionatutako produktuetan eta kirol ekipamenduetan.

Karbonoan oinarritutako NMen ekoizpena, garraioa, erabilpena eta deuseztapena kontuan hartuta, material horiek ingurunera isurtzea ekidin ezina da [16]. Hainbat bide direla medio karbonoan oinarritutako NMak itsasora iristen direnez, organismo itsastarretan eragin ditzaketen kalteen inguruko kezka zabaldu da. Behin uretan, hainbat faktore fisikokimiko zein biologikok eragiten diete, eta zenbait motatako kalteak sortaraz ditzakete [17]. Hortaz, NMek sor dezaketen toxizitateari buruzko ikerketak beharrezkoak dira NMen arriskua zehaztu ahal izateko [18].

Gaur egun ez dago jakiterik zein den karbonoan oinarritutako NM askoren kontzentrazioa ingurunean. Gehienetan, ingurunean egokitzen diren kontzentrazioak (ingelesetik environmentally relevant concentrations (ERC)) ordenagailuzko simuladoreen bitartez kalkulatzen dira eta uretan $\mu \mathrm{g} / \mathrm{L}$ eta $\mathrm{ng} / \mathrm{L}$ bitartean egon daitezke [19]. Esaterako, ingurune urtarretan espero den karbono-nanohodien kontzentrazioa 0,001-1000 $\mu \mathrm{g} / \mathrm{L}$ artekoa da. Grafenoaren ERC balioak ordea, ez dira kalkulatu oraindik, karbonoan oinarritutako NM nagusien artean egon arren. Ingurunean espero den grafeno kontzentrazioa karbono-nanohodienen antzekoa da, bi nanomaterial horiek ezaugarri eta aplikazio komunak dituztelako [16].

NMen tamaina txikiak zelulen mintzak eta bestelako muga biologikoak zeharkatzeko eta kalteak eragiteko gaitasuna eskaintzen die. Gainera, NMen tamaina txikiak haien azalera/bolumen erlazio handia dakar eta horrek haien erreaktibitatea emendatzen du, espazio gehiago dagoelako konposatu kimikoak NMarekin lotzeko, eta, hala, toxizitatea ere emendatzen 
du. Horrela, karbonoan oinarritutako NMek orokorrean eragin ditzaketen kalteen artean, hurrengoak azpimarratu daitezke: neurotoxizitatea, hepatotoxizitatea, nefrotoxizitatea, immunotoxizitatea, kardiotoxizitatea, genotoxizitatea, dermatotoxizitatea eta minbizia [14]. Karbonoan oinarritutako NMen artean, grafenoaren familiako NMen (grafenoa, grafeno oxidoa, grafeno oxido erreduzitua...) (2A. irudia) eta kabono-nanohodien (2B. irudia) toxizitatea ikertu da gehien. Grafenoaren familiako NMek eta karbono-nanohodiek itsas organismoetan eragiten dituzten kalte nabarmenenak hauek dira: estres oxidatiboa [20-26], genotoxizitatea [21], neurotoxizitatea [24], kalte histopatologikoak [25], metabolismo energetikoaren aldaketak [23, 24, 27], ugaltze gaitasunaren murriztapena, anormaltasunak arrautzen eklosioan eta enbrioien garapenean [27-30], kalteak igeri egiteko ahalmenean [29, 31, 32] eta heriotza-tasaren igoera [32, 33].

\section{MIKROPLASTIKO ETA NANOPLASTIKOAK}

Mikroplastikoak (MPak) $5 \mathrm{~mm}$ baino txikiagoak diren plastikozko partikulak dira [34, 35] eta, horien artean, $100 \mathrm{~nm}$ baino txikiagoak direnak nanoplastiko kontsideratzen dira. Plastiko makroskopikoen eraginak zabal ikertu diren arren, MP eta nanoplastikoen inguruko hausnarketa duela gutxi hasi da egiten [36]. MP eta nanoplastikoen jatorriari buruz, MP eta nanoplastikoak primarioak edo sekundarioak izan daitezke: MP eta nanoplastiko primarioak itsasoan topatzen ditugun era berean ekoitzi dira (produkzio industrialerako pikorrak, mostratxa-ipitzak, arropen zuntzak, produktu kosmetikoak...). Normalean, forma biribila dute edo 3 dimentsiodun egitura amorfoa eta tamaina nahiko zehatza [37-42]. MP eta nanoplastiko sekundarioak itsasoan dauden plastikozko partikula handiagoen apurketaz eratzen dira eta, gaur egun, itsasora heltzen den plastikozko zabor kantitate handia dela eta, esan daiteke ingurunean topatzen ditugun MP eta nanoplastiko gehienak sekundarioak direla [34, 42, 43]. Merkatuan topatzen ditugun plastiko mota nagusiak polipropilenoa (PP), polibinilozko kloruroa (ingelesetik Polyvinyl Chloride (PVC)), poliestirenoa (PS) (2C. irudia), poliuretanoa (PUR) eta polietilenoa (PE) dira, itsasoko eta itsas sedimentuetako plastiko mota nagusia ordea, PE da [34, 44, 45]. MP eta nanoplastiko-gehienak lurretik heltzen dira itsasora; batez ere, erreka, gainontzeko efluente eta ekaitzen ondorioz. Baina zuzenean ere heldu daitezke itsasora MP eta nanoplastikoak, bertan burutzen diren jardueren bitartez (arrantza, garraioa, aisialdiko jarduerak...) [46]. Plastikoen presentzia masiboari lotuta, MPen inguruko ikerketak esponentzialki igo dira azken urteotan eta artikulu askok adierazten dute MP eta nanoplastikoak itsaso eta ozeano guztietan topa daitezkeen kutsatzaileak direla [35, 47]. Horrela, itsas uretan topa daitezkeen MP eta nanoplastikoen zenbaketek adierazten dute datuak oso aldakorrak direla leku geografikoaren eta MPen izaeraren ara- 
bera [48-50]. Orokorrean, MP eta nanoplastikoen kontzentrazio altuenak eremu industrializatuetan eta zurrunbilo ozeanikoetan aurkitzen dira. Hala ere, MP eta nanoplastiko txikienak lagintzeko dauden zailtasunek kutsadura mota hori gutxiestea ekar lezakete [51].

A

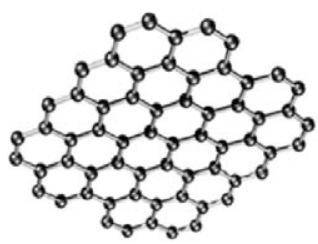

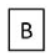

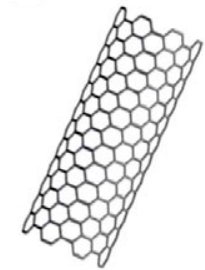

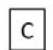

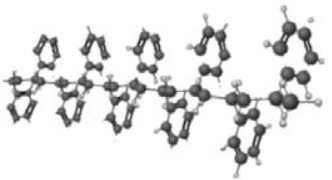

2. irudia. A: grafenoaren, B: karbono-nanohodien eta C: poliestirenoaren eredu atomikoak.

Frogatu da 220 espezie urtar baino gehiagok MPak irentsi dituztela, eta horrek sor ditzakeen eragin negatiboen inguruko kezka nabaria da [52]. Moluskuak, ekinodermoak, knidarioak, poliketoak, itsas hegaztiak, arrainak eta krustazeoak daude organismo horien artean [53-58]. Behin organismoan daudela, hurrengo eraginak behatu dira: MPen metaketa digestio hodiaren argian eta ondoriozko digestio kalteak edota MP eta nanoplastikoak ehunetan barneratzea eta ondoriozko toxizitatea [59]; zelula eta molekula mailako kalteak, batez ere, estres oxidatiboaren bitartez [51], organismo mailako kalteak, esaterako, elikaduran, biziraupenean, hazkuntzan eta ugalketan [60-63]. Gainera, organismoetan gertatzen den MP eta nanoplastikoen metaketak kate trofikoan zeharreko garraioa ahalbidetzen du [64-66].

\section{KUTSATZAILE ORGANIKO IRAUNKORRAK}

Kutsatzaile organiko iraunkorrak (ingelesetik Persistant Organic Pollutants (POP)) prozesu kimiko, biologiko eta fotolitikoen bitartez nekez degradatzen diren konposatu organikoak dira [67]. POPen artean hidrokarburo polizikliko aromatikoak (ingelesetik Polycyclic Aromatic Hydrocarbons (PAH)), bifenilo polikloratuak, naftaleno polikloratuak, polibromatutako difenil eterrak eta organokloratutako pestizidak daude, besteak beste [68-69]. Konposatu horietako asko kartzinogenikoak, mutagenikoak edota esteroidogenikoak dira eta sistema endokrinoan eragiteko gaitasuna izan dezakete. Konposatu hauek erregulatuta daude Europar Batasunean hainbat legediren bitartez [70] batez ere, 2001eko Estokolmoko konbentzioaz geroztik. 
POPen artean, PAHak itsasoan ia edonon topa daitezkeen kutsatzaileak dira, nahiz eta maiz kontzentrazio altuenak hiriguneetatik gertu aurki daitezkeen. PAHak era naturalean sor daitezkeen arren, haien jatorri nagusia jarduera antropogenikoa eta petrolio-isurketak dira [71, 72]. 20092012 aldian, Bizkaiko Golkoko sedimentuetan, 18 PAHren kontzentrazioa neurtzean, EPAk (ingelesetik Enviromental Protection Agency (EPA)) lehentasunezko kutsatzailetzat jotzen dituen 16 PAHak barne, osoko kontzentrazioak $66 \mu \mathrm{g} / \mathrm{kg}-7021 \mu \mathrm{g} / \mathrm{kg}$ pisu lehor ingurukoak izan ziren [73]. Kontzentrazio altuenak Ibaizabaleko estuarioan neurtu ziren; izan ere, Bizkaiko Golkoa gizakiaren presio handiena jasaten duen ingurua da [73]. Hurrengo urteetan (2011-2017), Bilboko estuarioan hartutako sedimentuetako PAHen kontzentrazioaren balioak aldakorrak izan ziren; azken neurketan, 2017koa, 12 PAHren metaketa $5.028 \mu \mathrm{g} / \mathrm{kg}$ pisu lehor izan zen [74]. Era berean, 2010ean Euskal Herriko kostaldean lagindutako muskuilue$\tan 13$ PAHren kontzentrazioa 146,8-557,1 $\mu \mathrm{g} / \mathrm{kg}$ pisu lehor bitartekoa izan zen; balio altuenak Bilbo inguruko muskuiluetan neurtu ziren [75].

Euskal kostaldeko hainbat tokitan 2009-2012 bitartean burututako beste ikerketa batean, Gorlizen lagindutako muskuiluetan behatutako kalteak sedimentuetan neurtutako PAHen kontzentrazioarekin erlazionatu ziren [76].

PAHak petrolio nahasteen toxizitatearen eragile nagusiak dira, nahiz eta zenbaitetan petrolioa osatzen duten milaka konposatuen artean portzentaia txikia baino ez diren. PAHak petrolioaren beste konposatu batzuk baino disolbagarriagoak dira uretan eta, ondorioz, bioeskuragarriagoak [77]. PAHen artean, bentzo(a)pirenoa (BaP) da ikertuenetako bat [78]. BaParen toxizitate profila oso zabala da: genotoxikoa, disruptore endokrinoa eta mutagenikoa izateaz gain, estres oxidatiboa eta minbizia sortzeko gai da. Ondorioz, nazioarteko zenbait erakundek eta legedik (adibidez: EPAk eta Europar Batasuneko Uraren Esparru Zuzentarauak [70]) lehentasunezko kutsatzaileen zerrendan dute. $\mathrm{BaPa}$ itsas ingurumenean aurki daitekeenez, ingurumen-toxikologian PAH eredu gisa erabiltzen da sarri $[79,80]$.

\section{KARBONOAN OINARRITUTAKO NANOMATERIALAK ETA MIKRO ETA NANOPLASTIKOAK KUTSATZAILE ORGANIKO IRAUNKORREN GARRAIATZAILE GISA INGURUNE URTARREAN}

Arestian aipatu bezala, NMek, mikro eta nanoplastikoek duten azalera/bolumen erlazio eta hidrofobizitate handia dela eta, arrisku gehigarri bat dute: POPen garraiatzaileak izan daitezke ingurune urtarretan. Hau da, NMek mikro eta nanoplastikoek ingurune urtarretan dauden POPak adsorbatu ditzakete eta haien eskuragarritasuna emendatu. Esaterako, grafenoa 
eta grafeno oxidoa, tindatzaileak [81-83], kutsatzaile organikoak [84, 85], metal astunak [86-88] eta farmakoak [89] uretatik bereganatzeko gai direla ikusi da. Zhu eta kideek [90] frogatu dute karbono-nanohodiz eratutako esponjek petrolioa adsorbatzeko gaitasun handiagoa dutela aztertutako beste konposatuek (PP eta artilezko feltroa) baino. Hainbat plastiko mota eta kutsatzaile ezberdinen arteko adsortzio eta desortzio dinamika karakterizatu eta gero, ikusi da bi mekanismo horiek polimeroaren eta konposatuaren menpe daudela [91]. Gainera, MPek adsorbatutako kutsatzaileak arrain, krustazeo, anelido eta bibalbioetara transferitzen direla ere frogatu da [92-100].

EHUko Zelulen Biologia Ingurumen Toxikologian (ZBIT) ikerketa taldeak ingurune urtar zein lehortarraren toxikologiaren esparruan dihardu 1985. urtetik. Besteak beste, nanotoxikologian ikerketa ugari burutu du eta, adibidez, lehenengoak izan dira zenbait NMen toxikotasuna frogatzen muskuiluen hemozitoetan in vitro testen bidez [101]. Batez ere, nanopartikula metalikoen toxizitatea aztertzea helburua zuten hainbat proiektu osatu eta gero, karbonoan oinarritutako NMen toxikotasuna aztertzeko proiektu berri bati ekin zaio, NAnoCarrierEra (NACE) proiektua, alegia. Proiektuaren helburu nagusia karbonoan oinarritutako NMek, mikro eta nanoplastikoek ingurune urtarretan izan dezaketen arriskua aztertzea da, bereziki, ingurunean dauden POPekin batera agertzen direnean. Helburu hori betetzeko, karbonoan oinarritutako NM, zenbait mikro eta nanoplastiko aukeratu dira: karbono-nanohodiak, grafenoa eta poliestirenozko mikro eta nanoplastikoak (2. irudia). POPen artean, $\mathrm{BaPa}$ hautatu da PAH eredu gisa eta urari egokitutako petrolioaren frakzioa PAHen nahasketa konplexu gisa. NM eta mikro eta nanoplastiko bakoitzak POPak bereganatzeko duen gaitasunaz gain, nahaste horiek sortarazitako kalteak aztertu dira.

Gainera, ekosistema urtarretako hainbat aldagai kontuan hartzeko, espezie anitzeko hurbilketa diseinatu da metodo alternatiboetan (3R filosofiari jarraiki animalien erabilera murriztu edo ordezkatzen dituzten metodoak) eta organismo ereduetan oinarrituta. Isochrysis galbana mikroalga eta Artemia sp. ornogabe itsastarrarekin toxizitate akutuko testak ari dira egiten. Horrez gain, toxizitate testak eta iraupen desberdinetako esperimentuak ari dira egiten Mytilus galloprovincialis muskuilu itsastarraren hemozito, enbrioi eta indibiduo helduetan eta ur gezetako arrain eredua den Danio rerio zebra arrainaren enbrioi zein indibiduo helduetan (3. irudia). Espezie bakoitzean, biomarkatzaileen bateria zabala ari da neurtzen karbonoan oinarritutako NMek, MPek eta nanoplastikoek (eta POPdun NMek, MPek eta nanoplastikoek) molekula, zelula eta organismo mailan izan ditzaketen eraginak aztertzeko. Bereziki «Troiako Zaldia» delako fenomenoa aztertu da [102, 103]; hau da, ea karbonoan oinarritutako NMek, MPek eta nanoplastikoek ingurune urtarretan dauden substantzia toxikoak adsorba- 
tzen dituzten eta, adsorbatzen dituzten kasuetan, ea adsortzio horrek kutsatzaileak bioeskuragarriago egiten dituen organismoentzat edo/eta bioeskuragarritasuna gutxitu egiten den eta beraz, kutsaduraren erremediaziorako baliatu daitezkeen.
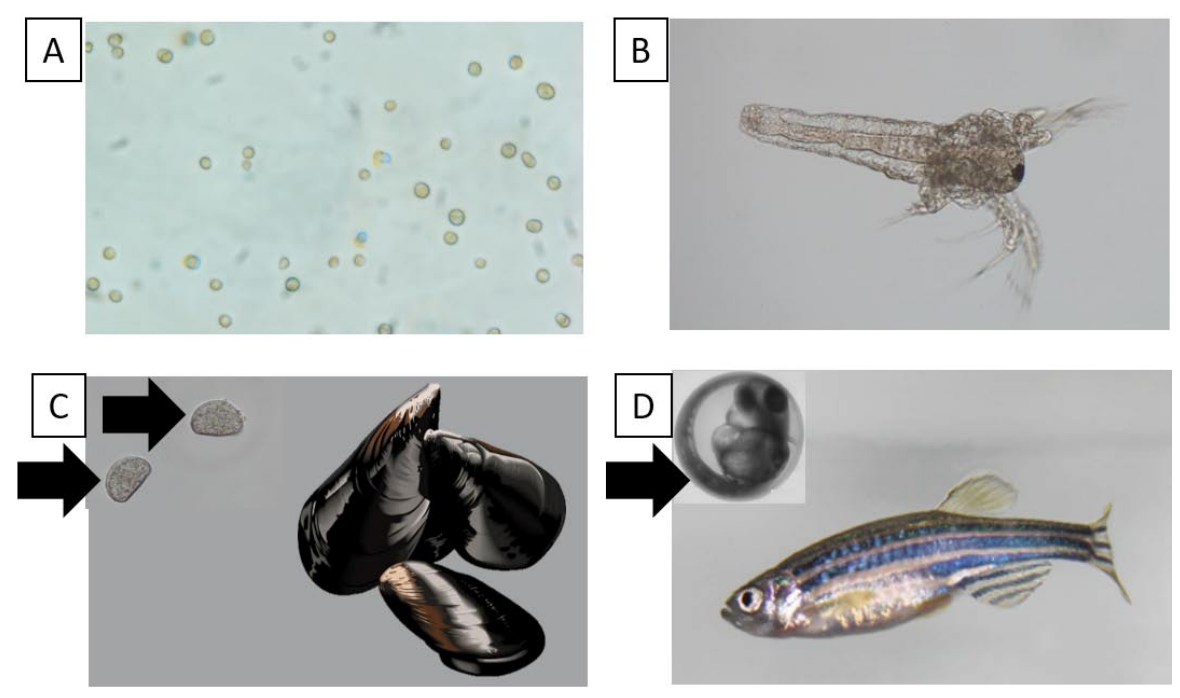

3. irudia. NACE proiektuan erabiltzen ari diren organismo ereduak: A: Isochrysis galbana mikroalga itsastarra, B: Artemia sp. krustazeoa, C: Mytilus galloprovincialis muskuilua eta D: Danio rerio zebra arraina. Geziek muskuilu eta zebra arrainen enbrioiak adierazten dituzte.

\section{MPen ETA POPdun MPen ERAGINA MUSKUILUETAN}

Mytilus spp. muskuilua organismo eredu moduan nabarmenki erabili ohi da kutsatzaileen metaketa eta haien eragina aztertzeko itsas ure$\tan$ [104]. Muskuiluak hain erabilgarri bihurtzen dituzten ezaugarrien artean, hurrengoak azpimarratu daitezke: 1 . nonahikotasuna; izan ere, muskuiluak mundu osoko kostaldeetan topa daitezke. 2; kate trofiko askoren parte dira. 3; gizakiak kontsumitzen dituenez, interes ekonomiko altuko taldea osatzen dute. 4; sesilak dira, eta horrenbestez leku zehatzen kutsadura mailaren adierazle egokiak, estres jakin baten aurrean ez baitute ihes egiterik. 5; haien elikadura estrategia dela eta, ur bolumen handiak iragazten dituzte etengabe eta, xenobiotikoak metabolizatzeko gaitasun baxua dutenez, ingurunean dauden kutsatzaileak metatzeko joera daukate. 6; kutsadura maila altuak jasateko gai dira baina, era berean, kutsadura maila baxuekiko sentikorrak dira eta horrek kutsatzaile mota ezberdinen pean garatzen duten erantzun mekanismoa zehaztea ahalbidetu du $[105,106]$. 
Muskuiluak hainbat biojarraipen programatan erabiltzen dira, bioindikatzaile gisa zein organismo behalari gisa, ingurune horietako kutsatzaileen bioeskuragarritasun maila zehazteko (adibidez, Mussel Watch programa Goldberg, 1976 [107]) eta kutsatzaileen pean organismoek emandako erantzunak aztertzeko (adibidez, MEDPOL-UNEP/RAMOGE, 1999 [108]). Bestalde, azken urteotan, muskuiluek duten iragazte gaitasun altuagatik eta beren sistema endolisosomiko garatuagatik, NMak, MPak eta nanoplastikoak eta haiei asoziatutako kutsatzaileak aztertzeko gako bilakatu dira $[59,95,97,109-113]$.

Horrela, NACE proiektuaren barruan ere, bi esperimentu burutu dira muskuiluekin, MPek eta POPdun MPek muskuiluetan izan dezaketen eragina aztertzeko. Lehenengo esperimentuan [100], bi tamaina ezberdindun MPen eragina konparatu zen, MPak bakarrik erabilita edo eredu den kutsatzaile organiko bat (BaP) adsorbatu ondoren; bigarren esperimentuan [114], berriz, tamaina bakarreko MPak aukeratu ziren eta MPek bakarrik zein petrolio nafteniko baten urari egokitutako frakzioaren (WAF) konposatuak adsorbatu ondoren eragindako kalteak aztertu ziren. Esperimentu horietan behatu bezala zein bibliografian irakur daitekeenez, MPen polimero motaren arabera [115], MPen tamainaren arabera [116] eta PAH motaren arabera [117], MPek PAH proportzio ezberdina adsorbatzen dute eta PAHen transferentzia maila ezberdina gertatzen da MPetatik muskuiluetara. MPen tamainaren menpeko biometaketa hori MPen azalera/bolumenarekin erlazionatuta dago; izan ere, erlazio hori zenbat eta handiagoa izan, PAHen adsortzioa eta desortzioa errazagoa da [115]. Adibidez, muskuiluak BaP kontzentrazio berdinarekin $(252 \mu \mathrm{g} / \mathrm{L})$ inkubatutako bi tamaina ezberdinetako $(4,5 \mu \mathrm{m}$ eta $0,5 \mu \mathrm{m})$ MPdun mikroalgekin elikatu eta gero, metatzen duten BaP kontzentrazioa altuago da MP txikiekin handiekin baino [100]. WAFarekin inkubatutako $4.5 \mu \mathrm{m}$-ko MPdun mikroalgekin elikatutako muskuiletan, ordea, ez da PAHrik biometatzen, WAFaren pean egondako muskuiluen ehunetan PAHak metatzen diren arren [114]. Hala ere, emaitza hori WAFaren konposizioak azal lezake; izan ere, WAFaren karakterizazioak erakutsi du PAH lurrunkorren (nagusiki naftalenoa, azenaftenoa, fluorenoa eta fenantrenoa) kontzentrazio oso baxuek eratzen dutela [117].

Lan askotan azpimarratu da MPen tamainak baduela garrantzia muskuiluek MPak barneratu eta asimilatzeko orduan [109, 118-121]. Orain arte egindako ikerketen arabera, ordea, ez dago argi zein MP tamainak daukan organismoetan metatzeko gaitasun handiena, ezta metaketa hori polimero motaren araberakoa den ere [121]. Behaketa histologikoen bidez MPak hainbat organotan topatu diren arren, hala nola zakatzak, gonada eta hemolinfa, MP gehienak digestio aparatuan behatu dira $[59,95,97,99,100,109,122]$. Horrek indartu egiten du orain arte proposatutako MPen barneraketa-mekanismo nagusia: MPek zakatzak ukitzen dituzte eta, zilioen mugimenduaren bitartez, MPak ahora 
garraiatzen dira; ahoan, irentsi egiten dira eta digestio aparatuan barneratu $[59,109,118,123]$. Animalien barnean, POPdun MPek zein MP garbiek hantura erantzun ez-espezifikoak eragiten dituztela ikusi da, hala nola fibrosia, zelula arreen metaketa ehun konektibo zein digestio traktuko epitelioan [100], infiltrazio hemozitikoak, $[99,100,123]$ eta granulozitomak [59]. Hala ere, MPen barneraketak eragin ditzakeen kalteen inguruko adostasuna horraino heltzen da; izan ere, POPdun MP zein MP garbien pean egondako muskuiluetan erantzun ezberdinak aurkitu baitira hainbat biomarkatzailetan. Esaterako, MPekin bakarrik eta fluorantenoarekin egondako muskuiluetan, katalasa zein beste zenbait biomarkatzaileren arabera, estres oxidatiboa ematen da [97]. Muskuiluak MPekin bakarrik edo pirenodun MPekin egotean, ordea, ez da aldatzen katalasa entzimaren jarduera [95]. WAFdun MPekin egondako muskuiluen hemozitoen katalasa jarduera ere ez da aldatzen [114] baina BaPdun MPekin egondako muskuiluen kasuan, ordea, erantzun biak ikusi dira, katalasaren erantzun eza [99] eta katalasa jardueraren murriztapena hemozitoetan [100]. Azken lan horretan, gainera, hemozitoen bideragarritasunaren murriztapena ematen da 26 egun eta gero [100]. Muskuiluak WAFdun MP eta MP garbien pean egon ostean, ordea, ez da behatu hemozitoen bideragarritasuna murrizten denik [114].

MPek sistema antioxidatzailea aldatzeko erakutsitako gaitasuna genotoxizitatearekin egon daiteke lotuta [59, 97, 124, 125]. Horrela, DNA mailako kalteak aztertzerakoan ere, emaitza ezberdinak deskribatu dira bibliografian. Zenbaitetan ez da genotoxizitaterik behatu MPen pean, pirenodun [95] zein BaPdun [99] MPen pean egondako itsas muskuiluetan, ezta 90 egunez MPen pean egondako ur gezetako muskuiluetan (Perna perna) ere [126]. Aitzitik, Scrobicularia plana 7 egunez $1 \mathrm{mg} / \mathrm{L}$ PSzko MPen pean [127] egon ondoren, eta M. galloprovincialis 96 orduz $0,05 \mathrm{mg} / \mathrm{L}-50 \mathrm{mg} / \mathrm{L}$ PSzko nanoplastikoen pean [128] egon ostean, kalteak behatu dira DNA mailan. MPen pean egondako muskuiluetan ere, DNA mailako kalte nabarmenak behatu dira [114]. Gainera, BaPdun tamaina ezberdinetako MPak zein MP garbiak konparatzean, 26 egunez egondako muskuiluetan DNA mailako kalteek MPen tamainarekiko lotura handiagoa dutela ikusi da adsorbatutako BaParekiko baino [100].

Egoera fisiologiko arruntean muskuiluen digestio hodietako digestio zelulen kopurua zelula basofilikoena baino ugariagoa da baina, estres pean, digestio zelulak galdu egiten dira eta zelula basofilikoen proportzioa emendatu egiten da [129-132]. Esate baterako, 0,5 $\mu \mathrm{m}$-ko BaPdun MPen eta MP hutsen pean 7 egunez egondako muskuiluetan zelula basofilikoen dentsitate bolumetrikoa emendatu egiten da [100] eta neurtutako balioa Bignell eta kideek [132] estres egoeretan neurtutako atalasearen gainetik dago. Digestio hodien egituran, berriz, BaPak efektu gehigarria erantsi die MPei epe luzera. Izan ere, $0,5 \mu \mathrm{m}$-ko BaPdun MPen pean egondako muskuiluen 
digestio hodien epitelioa $0,5 \mu \mathrm{m}$-ko MP garbien pean egondako muskuiluen epitelioa baino finagoa da. Digestio epitelioaren mehetze hori hidrokarburoen toxizitatearekin lotu izan da [131,133] eta muskuiluen digestio gaitasuna murriztu lezakela proposatu da [130].

Organismo mailan gertatzen diren erantzunak ikerketa batetik bestera ezberdinak dira. Muskuilu eta anelidoetan, esaterako, MPen pean egon ondoren, metabolismo orokorraren igoera [119] deskribatu da, otarrainxketan, ordea, jaitsiera [134]. Bi erantzun horiek estresari aurre egiteko energia erabilgarria emendatzea bilatzen dute eta lotura zuzena dute elikadura eta irensketa tasetan behatutako aldaketekin. MPen pean egondako bibalbioetan, elikadura eta iragazketa tasaren emendioa [135] zein inhibizioa $[60,63,136]$ deskribatu dira. Esate baterako, BaPdun $0,5 \mu \mathrm{m}$-ko MPen eta $0,5 \mu \mathrm{m}$ eta $4,5 \mu \mathrm{m}$-ko MP garbien pean egondako muskuiluen elikagaien absortzioaren efizientzia emendatu egiten da 26 egun eta gero. Gainera, BaPdun 0,5 $\mu \mathrm{m}$-ko MPen eta $0,5 \mu \mathrm{m}$-ko MP garbien pean egondako muskuiluek energia erabilgarri gehiago dute 7 eta 26 egunen buruan, hurrenez hurren [100]. WAFdun 4,5 $\mu \mathrm{m}$-ko MPen pean egondako muskuiluetan ez da aldatzen elikagaien absortzioaren efizientzia ezta energia erabilgarriaren maila ere; aldiz, 4,5 $\mu \mathrm{m}$-ko MP garbien pean egondako muskuiluetan absortzioaren efizientzia murriztu egiten da [114]. Erantzun desberdin horiek ez dira MPen polimero mota, tamaina eta kontzentrazioaren araberakoak soilik, aztertutako espeziaren araberakoak ere badirela ikusi da. Izan ere, esperimentu berdina bi bibalbio espezierekin (Ostrea edulis eta M. edulis) burutzean, MPen aurrean duten erantzun mekanismoa kontrakoa dela ikusi da [137]. Baldintza berdintsuetan, ostrek iragazketa tasa emendatzen duten bitartean, muskuiluek murriztu egiten dute. Digestioarekin erlazioa daukaten mekanismoetan, ordea, antzeko erantzunak behatu dira MPen pean egondako ostra eta muskuiluetan. Mikroalgen kontsumoaren emendioa ikusi da bi tamainatako MPen pean egondako ostretan (Crassostrea gigas) [135], eta glikolisia eta digestio jardueraren indukzioa, MPen pean egondako muskuiluetan [97]. Digestioaren efizientziaren emendio hori estresari aurre egiteko babes mekanismoak eskatzen duen energia gastu gehigarria konpentsatzeko dela uler daiteke.

MPek digestio gaitasunean zein energia erabilgarriaren mailan eragindako aldaketek ugalkortasuna baldintzatu ditzakete [134, ]. Horrela, 2 hilabetez MPen pean egondako ostren obozitoen kopurua, obozitoen diametroa eta espermaren mugikortasuna murriztu egiten da [135]. Gainera, MPek hurrengo belaunaldia ere kaltetu lezakete; izan ere, MPen pean egondako ostren gametoen ernalketatik garatutako enbrioi gutxiago heltzen da D larba estadiora, kontrolarekin alderatuta [135]. Aitzitik, POPdun MPek bibalbioen ugalketa gaitasunean duten eragina ikertzeke dago [138].

Laburbilduz, MPek POPak adsorbatzeko duten gaitasuna MP motaren eta POP konposatuaren menpe dago. PSzko MPen kasuan, adibidez, adsor- 
tzioa emendatu egiten da MParen tamaina txikitzen den heinean (4. irudia). Frogatu da MPek adsorbatutako POPak, BaP kasu, organismoetara transferitzen direla eta progresiboki ehunetan meta daitezkeela. MPek bakarrik zein POPdun MPek molekula mailatik organismo mailara eragin dezakete kaltea; gainera, zenbaitetan, adsorbatutako konposatuek, MPek bakarrik eragin dezaketen kaltea emendatu egiten dute (4. irudia).

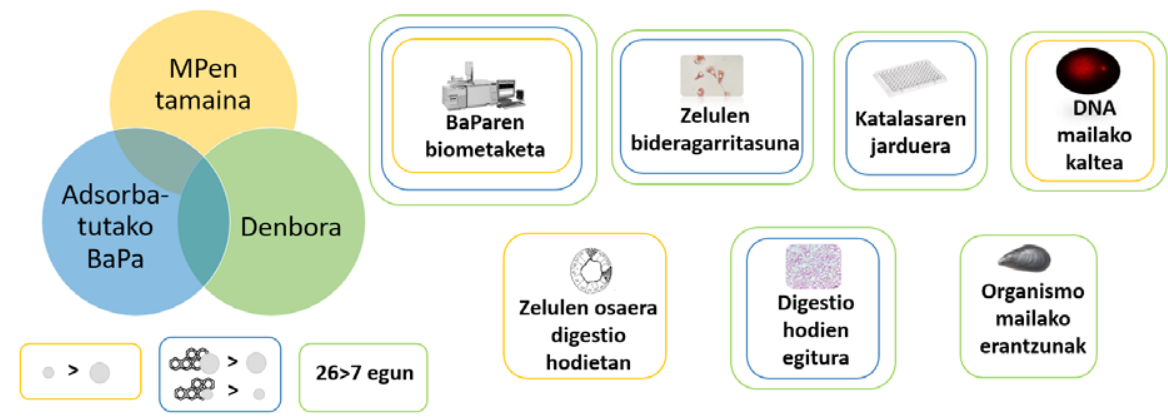

4. irudia. MPen tamainak (horiz), $\mathrm{BaP}$ adsorbatuak (urdinez) eta tratamenduaren iraupenak (berdez) muskuiluetan neurtutako hainbat biomarkatzailetan duten eragina laburbiltzen duen eskema (Gonzalez-Soto et al., 2019-tik moldatua [100]).

\section{AURRERA BEGIRA}

Lan asko gelditzen da egiteke itsasoan gerta daitezkeen balizko egoerak simulatzeko. Esperimentu ugari burutu beharko da oraindik tamaina, mota eta forma ezberdineko NM, mikro eta nanoplastikoekin, bakarrik zein POPekin konbinatuta, NM, mikro eta nanoplastikoen arriskua ezagutzeko eta inguruko kutsatzaileen garraiatzaile moduan izan dezaketen funtzioa ulertzeko. Batez ere, gero eta NM mota ezberdin gehiago ekoizten dela kontuan hartuta, eta haien ezaugarrietan aldaketa txikiek NMek inguruan izan dezaketen portaera baldintzatu lezaketela kontuan hartuta, kutsatzaileak adsorbatzeko eta garraiatzeko gaitasuna barne.

\section{ESKER ONAK}

Ikerketa hau MINECOk (NACE-CTM2016-81130-R proiektua), Eusko Jaurlaritzak (N. Gonzalez Sotoren Doktoretza aurreko beka, Ikerketa Talde Kontsolidatuak IT810-13 eta IT1302-19) eta UPV/EHUk (UFI11/37, Ikerketa Errektoreordetzako laguntza PLASTOX) finantziatu dute. Lan hau EBko PLASTOX proiektuaren barnean burutu da (JPI Oceans 005/2015). 
Karbonoan oinarritutako nanomaterialen eta mikro eta nanoplastikoen eragina kutsatzaile organiko iraunkorren garraiatzaile gisa organismo itsastarretan

\section{BIBLIOGRAFIA}

[1] NEL, A., XIA, T., MADLER, L., LI, N. 2006. Toxic potential of materials at the nanolevel. Science 311, 622-627.

[2] POKROPIVNY, V.V., SKOROKHOD, V.V. 2007. Classification of nanostructures by dimensionality and concept of surface forms engineering in nanomaterial science. Materials Science and Engineering: C 27,990-993.

[3] QUESADA-GONZÁLEZ, D., MERKOÇI, A. 2018. Nanomaterial-based devices for point-of-care diagnostic applications. Chemical Society Reviews $\mathbf{4 7}$, 4697-4709.

[4] HEINZ, H., PRAMANIK C., HEINZ O., DING Y., MISHRA R.K., MARCHON D., FLATT, R.J., LOPIS, I.E., LLOP, J., MOYA, S., ZIOLO, R.F. 2017. Nanoparticle decoration with surfactants: molecular interactions, assembly, and applications. Surface Science Reports 72, 1-58.

[5] HOOD, E. 2004. Nanotechnology: Looking as we leap. Environmental Health Perspectives 112, 741-749.

[6] IIJIMA, S., ICHIHASHI, T. 1993. Single-shell carbon nanotubes of 1-nm diameter. Nature 363, 603-605.

[7] NOVOSELOV, K.S., GEIM, A.K., MOROZOV, S., JIANG, D., KATSNELSON, M., GRIGORIEVA, I., FIRSOV, A.A. 2005. Two-dimensional gas of massless Dirac fermions in graphene. Nature 438, 197-200.

[8] GEIM, A.K., NOVOSELOV, K.S. 2007. The rise of graphene. Nature Materials $6,183-191$.

[9] GEIM, A.K. 2009. Graphene: status and prospects. Science 324, 15301534.

[10] DOWLING, A., CLIFT, R., GROBERT, N., HUTTON, D., OLIVER, R., O’NEILL, O., PETHICA J., PIDGEON, N., PORRITT, J., RYAN, J. et al. 2004. Nanoscience and nanotechnologies: opportunities and uncertainties. London The Royal Society of Royal Academy of Engineering 46, 6-18.

[11] NETO, V.F., VAZ, R., ALI, N., OLIVEIRA, M.S.A. GRÁCIO, J. 2008. Performance of sub-micron diamond films coated on mould inserts for plastic injection moulding. Journal of Materials Science 43, 3392-3399.

[12] NETO, V.F., SANTOS, J.A., ALBERTO, N.J., PINTO, J.L., NOGUEIRA, R.N., GRÁCIO, J. 2011. Evaluation of diamond coatings on optical fibre sensors for biological use. Journal of Nanoscience and Nanotechnology 11, 5408-5412.

[13] DINADAYALANE, T.C., LESZCZYNSKI, J. 2010. Remarkable diversity of carbon-carbon bonds: structures and properties of fullerenes, carbon nanotubes, and graphene. Structural Chemistry 21, 1155-1169.

[14] MADANNEJAD, R., SHOAIE, N., JAHANPEYMA, F., DARVISHI, M.H., AZIMZADEH, M., JAVADI, H. 2019. Toxicity of carbon-based nanomaterials: Reviewing recent reports in medical and biological systems. Chemicobiological Interactions 307, 206-222.

[15] The nanodatabase: http://nanodb.dk/en/search-database/ 
[16] DE MARCHI, L., PRETTI, C., GABRIEL, B., MARQUES, P.A.A.P., FREITAS, R., NETO, V. 2018a. An overview of graphene materials: Properties, applications and toxicity on aquatic environments. Science of the Total Environment 631-632, 1440-1456.

[17] HE, K., CHEN, G., ZENG, G., PENG, M., HUANG, Z., SHI, J., HUANG, T. 2017. Stability, transport and ecosystem effects of graphene in water and soil environments. Nanoscale 9, 5370-5388.

[18] CORSI, I., CHERR, G.N., LENIHAN, H.S., LABILLE, J., HASSELLOV, M., CANESI, L., DONDERO, F., FRENZILLI, G., HRISTOZOV, D., PUNTES, V., DELLA TORRE, C., PINSINO, A., LIBRALATO, G., MARCOMINI, A., SABBIONI, E., MATRANGA, V. 2014. Common strategies and technologies for the ecosafety assessment and design of nanomaterials entering the marine environment. ACS Nano 8, 9694-9709.

[19] SUN, T.Y., BORNHÖFT, N.A., HUNGERBÜHLER, K., NOWACK, B. 2016. Dynamic probabilistic modeling of environmental emissions of engineered nanomaterials. Environmental Science \& Technology 50, 4701-4711.

[20] PRETTI, C., OLIVA, M., DI PIETRO, R.,MONNI, G. CEVASCO, G. CHIELLINI, F., POMELLI, C., CHIAPPE, C. 2014. Ecotoxicity of pristine graphene to marine organisms. Ecotoxicology and Environmental Safety 101, 138-145.

[21] ZHAO, J., WANG, Z., WHITE, J.C., XING, B. 2014. Graphene in the aquatic environment: adsorption, dispersion, toxicity and transformation. Environmental Science \& Technology 48, 9995-10009.

[22] KHALID, P., HUSSAIN, M.A., SUMAN, V.B., ARUN, A.B. 2016. Toxicology of carbon nanotubes - A Review. Journal of Applied Engineering Research 11,148-157.

[23] DE MARCHI, L., NETO, V., PRETTI, C., FIGUEIRA, E., BRAMBILLA, L., RODRIGUEZ-DOUTON, M.J, ROSSELLA, F., TOMMASINI, M., FURTADO, C., SOARES, A.M.V.M., FREITAS, R. 2017. Physiological and biochemical impacts of graphene oxide in polychaetes: The case of Diopatra neapolitana. Comparative Biochemistry \& Physiology Part C 193, 50-60.

[24] DE MARCHI, L., NETO, V., PRETTI, C., FIGUERA, E., CHIELLINI, F., MORELLI, A., SOARES, A.M.V.M., FREITAS, R. 2018b. Toxic effects of multi-walled carbon nanotubes on bivalves: Comparison between functionalized and non functionalized nanoparticles. Science of the Total Environment 622-623, 1532-1542.

[25] FERNANDES, A.L., JOSENDE, M.E., NASCIMENTO, J.P., SANTOS, A.P., SAHOO, S.K., RODRIGUES DA SILVA JUNIOR, F.M., ROMANO, L.A., FURTADO, C.A., WASIELESKY, W., MONSERRAT, J.M., VENTURA-LIMA, J. 2017. Exposure to few-layer graphene through diet induces oxidative stress and histological changes in the marine shrimp Litopenaeus vannamei. Toxicology Research 6, 205-214.

[26] KATSUMITI, A., TOMOVSKA, R., CAJARAVILLE, M.P. 2017. Intracellular localization and toxicity of graphene oxide and reduced graphene oxide 
Karbonoan oinarritutako nanomaterialen eta mikro eta nanoplastikoen eragina kutsatzaile organiko iraunkorren garraiatzaile gisa organismo itsastarretan

nanoplatelets to mussel hemocytes in vitro. Aquatic Toxicology 188, 138147.

[27] CHOWDHURY, S.M., SBHAM DASGUPTA, S., MCELROY, A.E., SITHARAMAN, B. 2014. Structural disruption increases toxicity of graphene nanoribbons. Journal of Applied Toxicology 34, 1235-46.

[28] MESARIČ, T., SEPČIČ, K., DROBNE, D., MAKOVEC, D., FAIMALI, M., MORGANA, S., FALUGI, C., GAMBARDELLA, C. 2015b. Sperm exposure to carbon-based nanomaterials causes abnormalities in early development of purple sea urchin (Paracentrotus lividus). Aquatic Toxicology 163 158-166.

[29] ZHU, S., LUO, F., CHEN, W., ZHU, B., WANG, G. 2017. Toxicity evaluation of graphene oxide on cysts and three larval stages of Artemia salina. Science of the Total Environment 595, 101-109.

[30] YI, X., YU, M., LI, Z. CHI, T., JING, S., ZHANG, K., LI, W., WU, M. 2019. Effect of multi-walled carbon nanotubes on the toxicity of triphenyltin to the marine copepod Tigriopus japonicus. Bulletin of Environmental Contamination and Toxicology 102, 789-794.

[31] MESARIČ, T., SEPČIČ, K., PIAZZA, V., GAMBARDELLA, C., GARAVENTA, F., DROBNE, D., FAIMALI, M. 2013. Effects of nano carbon black and single-layer graphene oxide on settlement, survival and swimming behaviour of Amphibalanus amphitrite larvae. Journal of Chemical Ecology 29, 643-652.

[32] MESARIČ, T., GAMBARDELLA, C., MILIVOJEVIĆ, T., FAIMALI, M., DROBNE, D., FALUGI, C., MAKOVEC, D., JEMEC, A., SEPČIĆ, K. 2015a. High surface adsorption properties of carbon-based nanomaterials are responsible for mortality, swimming inhibition and biochemical responses in Artemia salina larvae. Aquatic Toxicology 163, 121-129.

[33] LU, J., ZHU, X., TIAN, S., LV, X., CHEN, Z., JIANG, Y., LIAO, X., CAI, Z., CHEN, B. 2018. Graphene oxide in the marine environment: Toxicity to Artemia salina with and without the presence of Phe and $\mathrm{Cd}^{2}$. Chemosphere 211, 390-396.

[34] ANDRADY, A.L. 2011. Microplastics in the marine environment. Marine Pollution Bulletin 62, 1596-1605.

[35] COLE, M., LINDEQUE, P., HALSBAND, C., GALlOWAY, T.S. 2011. Microplastics as contaminants in the marine environment: a review. Marine Pollution Bulletin 62, 2588-2597.

[36] BARNES, D.K.A., GALGANI, F., THOMPSON, C.R., BARLAZ, M. 2009. Accumulation and fragmentation of plastic debris in global environments. Philosophical Transactions of the Royal Society B: Biological Sciences B364, 1985-1998.

[37] ZITKO, V., HANLON, M. 1991. Another source of pollution by plastics: skin cleaners with plastic scrubbers. Marine Pollution Bulletin 22, 41-42.

[38] GREGORY, M.R. 1996. Plastic 'scrubbers' in hand cleansers: a further (and minor) source for marine pollution identified. Marine Pollution Bulletin 32, 867-871. 
[39] HINTERSTEINER, I., HIMMELSBACH, M., BUCHBERGER, W.W. 2015. Characterization and quantitation of polyolefin microplastics in personal-care products using high-temperature gel-permeation chromatography. Analytical and Bioanalytical Chemistry 407, 1253-1259.

[40] LASSEN, C., HANSEN, F. S., MAGNUSSON, K., NORÉN, F., HARTMANN, B.N.I., JENSEN, R.P. et al. 2015. Microplastics-occurrence, effects and sources of releases to the environment in Denmark. Environmental project No. 1793. Copenhagen: Environment Protection Agency, Ministry of Environment and Food of Denmark.

[41] NAPPER, I.E., BAKIR, A., ROWLAND, S.J., THOMPSON, R.C. 2015. Characterisation, quantity and sorptive properties of microplastics extracted from cosmetics. Marine Pollution Bulletin 99, 178-185.

[42] DUIS, K., COORS, A. 2016. Microplastics in the aquatic and terrestrial environment: sources (with a specific focus on personal care products), fate and effects. Environmental Sciences Europe 28, 2.

[43] HIDAlGO-RUZ, V., GUTOW, L., THOMPSON, R.C., THIEL, M. 2012. Microplastics in the marine environment: a review of the methods used for identification and quantification. Environmental Science \& Technology 46, 3060-3075.

[44] ENGLER, R.E. 2012. The complex interaction between marine debris and toxic chemicals in the ocean. Environmental Science \& Technology 46 , 12302-12315.

[45] SUARIA, G., AVIO, C.G., MINEO, A., LATTIN, G.L., MAGALDI, M.G., BELMONTE, G., MOORE, C.J., REGOLI, F., ALIANI, S. 2016. The Mediterranean plastic soup: synthetic polymers in Mediterranean surface waters. Scientific Reports 6, 37551.

[46] KÜHN, S., REBOLLEDO, E.L.B., VAN FRANEKER, J.A. 2015. Deleterious effects of litter on marine life. In M. Bergmann, L. Gutow \& M. Klages (Eds.), Marine anthropogenic litter (75-116). Berlin: Springer.

[47] BROWNE, M.A., CRUMP, P., NIVEN, S.J., TEUTEN, E., TONKIN, A., GALLOWAY, T., THOMPSON, R. 2011. Accumulation of microplastic on shorelines worldwide: sources and sinks. Environmental Science \& Technology 45, 9175-9179.

[48] NORÉN, F., NAUSTVOLL, F. 2010. Survey of microscopic anthropogenic particle in Skagerrak. Report commissioned by Klimaog Forureningsdirektoratet (Oslo, Norway).

[49] DESFORGES, J.P.W., GALBRAITH, M., DANGERFIELD, N., ROSS, P.S. 2014. Widespread distribution of microplastics in subsurface seawater in the NE Pacific Ocean. Marine Pollution Bulletin 79, 94-99.

[50] BAINI, M., FOSSIA, M.C., GALLIA, M., CLABIANIA, I., CAMPANIA, T., FINOIAC, M.G., PANTIA, C. 2018. Abundance and characterization of microplastics in the coastal waters of Tuscany (Italy): the application of the MSFD monitoring protocol in the Mediterranean Sea. Marine Pollution Bulletin 133, 54-552. 
Karbonoan oinarritutako nanomaterialen eta mikro eta nanoplastikoen eragina kutsatzaile organiko iraunkorren garraiatzaile gisa organismo itsastarretan

[51] LUSHER, A. 2015. Microplastics in the marine environment: Distribution, interactions and effects. In M. Bergmann, L. Gutow \& M. Klages (eds.), Marine anthropogenic litter (245-308). Berlin: Springer.

[52] LUSHER, A.L., WELDEN, N.A., SOBRAL, P., COLE, M. 2017. Sampling, isolating and identifying microplastics ingested by fish and invertebrates. Analytical Methods 9, 1346-1360.

[53] HOSS, D.E., SETTLE, L.R. 1990. Ingestion of plastics by teleost fishes. In: Shomura, R.S., Godfrey, M.L. (Eds.), Proceedings of the Second International Conference on Marine Debris. US Department of Commerce, NOAA Technical Memo, Honolulu, HI, 693-709.

[54] JUMARS, P.A. 1993. Gourmands of mud: diet selection in marine deposit feeders. In: Hughes, R.N. (Ed.), Mechanisms of Diet Choice. Blackwell Scientific Publishers, Oxford, 124-156.

[55] THOMPSON, R.C., OLSEN, Y., MITCHELL, R.P., DAVIS, A., ROWLAND, S.J., JOHN A.W., RUSSELL A.E. 2004. Lost at sea: where is all the plastic? Science. 304, 838.

[56] WARD, J.E., SHUMWAY, S.E. 2004. Separating the grain from the chaff: particle selection in suspension and deposit-feeding bivalves. Journal of Experimental Marine Biology and Ecology 300, 83-130.

[57] VAN FRANEKER, J.A., BLAIZE, C., DANIELSEN, J., FAIRCLOUGH, K., GOLLAN, J., GUSE, N., HANSEN, P.L., HEUBECK, M., JENSEN, J.K., LE GUILLOU, G., OLSEN, B., OLSEN, K.O., PEDERSEN, J., STIENEN, E.W.M., TURNER, D.M. 2011. Monitoring plastic ingestion by the northern fulmar Fulmarus glacialis in the North Sea. Environmental Pollution 159, 2609-2615.

[58] HALL, N.M., BERRY, K.L.E., RINTOUL, L., HOOGENBOOM, M.O. 2015. Microplastic ingestion by scleractinian corals. Marine Biology 162, 725-732.

[59] VON MOOS, N., BURKHARD-HOLM, P., KOHLER, A. 2012. Uptake and effects of microplastics on cells and tissue of the blue mussel Mytilus edulis L. after an experimental exposure. Environmental Science \& Technology 46, 11327-11335.

[60] WEGNER, A., BESSELING, E., FOEKEMA, E.M., KAMERMANS, P., KOELMANS, A.A. 2012. Effects of nanopolystyrene on the feeding behavior of the blue mussel (Mytilus edulis L.). Environmental Toxicology and Chemistry 31, 2490-2497.

[61] WRIGHT, S.L., ROWE, D., THOMPSON, R.C., GALLOWAY, T.S. 2013. Microplastic ingestion decreases energy reserves in marine worms. Current Biology 23, R1031-R1033.

[62] WATTS, A.J., URBINA, M.A., CORR, S., LEWIS, C., GALLOWAY, T.S. 2015. Ingestion of plastic microfibers by the crab Carcinus maenas and its effect on food consumption and energy balance. Environmental Science \& Technology 49, 14597-14604.

[63] RIST, S.E., ASSIDQI, K., ZAMANI, N.P., APPEL, D., PERSCHKE, M., HUHN, M., LENZ M. 2016. Suspended micro-sized PVC particles impair 
the performance and decrease survival in the Asian green mussel Perna viridis. Marine Pollution Bulletin 111, 213-220.

[64] FARRELL, P., NELSON, K. 2013. Trophic level transfer of microplastic: Mytilus edulis (L.) to Carcinus maenas (L.). Environmental Pollution 177, 1-3.

[65] BATEL, A., LINTI, F., SCHERER, M., ERDINGER, L., BRAUNBECK, T. 2016. The transfer of benzo[a]pyrene from microplastics to Artemia nauplii and further to zebrafish via a trophic food web experiment - CYP1A induction and visual tracking of persistent organic pollutants. Environmental Toxicology and Chemistry 35, 1656-1666.

[66] SANTANA, M.F.M., MOREIRA, F.T., TURRA, A. 2017. Trophic transference of microplastics under a low exposure scenario: insights on the likelihood of particle cascading along marine food-webs. Marine Pollution Bulletin 121, 154-159.

[67] RITTER, L., SOLOMON, KR., FORGET, J., STEMEROFF, M., O'LEARY, C. 2007. «Persistent organic pollutants». United Nations Environment Programme. Retrieved 2007-09-16 (4).

[68] CARLSSON, P., CROSSE, J.D., HALSAlL, C., EVENSET, A., HEIMSTAD, E.S., HARJU M. 2016. Perfluoroalkylated substances (PFASs) and legacy persistent organic pollutants (POPs) in halibut and shrimp from coastal areas in the far north of Norway: Small survey of important dietary foodstuffs for coastal communities. Marine Pollution Bulletin 105, 81-7.

[69] ODABASI, M., DUMANOGLU, Y., OZGUNERGE, E., TUNA, G. 2016. Investigation of spatial distributions and sources of persistent organic pollutants (POPs) in a heavily polluted industrial region using tree components. Chemosphere 160, 114-125.

[70] U.E. Water Framework Directive, 2008. Environmental Quality Standards Directive (EQSD). 105/EC. http://ec.europa.eu/environment/water/waterframework/priority_substances.htm

[71] ABDEL-SHAFY, H.I., MANSOUR, M.S.M. 2016. A review on polycyclic aromatic hydrocarbons: Source, environmental impact, effect on human health and remediation. Egyptian Journal of Petrolium 25, 107-123.

[72] MEADOR, J.P., STEIN, J.E., REICHERT, W.L., VARANASI, U. 1995. Bioaccumulation of polycyclic aromatic hydrocarbons by marine organisms. Reviews of Environmental Contamination and Toxicology 143,79-165.

[73] LEGORBURU, I., RODRIGUEZ, J.G., VALENCIA, V., SOLAUN, O., BORJA, A., MILLAN, E., GALPARSORO, I., LARRETA, J. 2014. Sources and spatial distribution of polycyclic aromatic hydrocarbons in coastal sediments of the Basque Country (Bay of Biscay). Chemistry and Ecology 30, 701-718.

[74] BRIAUdEAU, T., ZORITA, I., CUEVAS, N., FRANCO, J., MARIGÓMEZ, I., IZAGIRRE, U. 2019. Multi-annual survey of health status disturbance in the Bilbao estuary (Bay of Biscay) based on sediment 
Karbonoan oinarritutako nanomaterialen eta mikro eta nanoplastikoen eragina kutsatzaile organiko iraunkorren garraiatzaile gisa organismo itsastarretan

chemistry and juvenile sole (Solea spp.) histopathology. Marine Pollution Bulletin 145, 126-137.

[75] BELlas, J., ALBENTOSA, M., VIDAL-LIÑAL, L., BESADA, V., FRANCO, M.A., FUMEGA, J., GONZÁLEZ-QUIJANO, A., VIÑAS, L., BEIRAS, R. 2014. Combined use of chemical, biochemical and physiological variables in mussels for the assessment of marine polllution along the N-NW Spanish coast. Marine Environmental Research 96, 105-117.

[76] CUEVAS, N., ZORITA, I., COSTA, P.M., FRANCO, J., LARRETA, J. 2015. Development of histopathological indices in the digestive gland and gonad of mussels: Integration with contamination levels and effects of counding factors. Aquatic Toxicology 162, 152-164.

[77] CARLS, M.G., MEADOR, J.P. 2009. A perspective on the toxicity of petrogenic PAHs to developing fish embryos related to environmental chemistry. Human and Ecological Risk Assessment 15, 1084-1098.

[78] CCME (Canadian Council of Ministers of the Environment). Canadian soil quality guidelines for potentially carcinogenic and other PAHs: scientific criteria document. CCME: Winnipeg: 2010.

[79] BANNI, M., SFORZINI, S., ARLT, V.M., BARRANGER, A., DALLAS, L.J., OLIVERI, C., AMINOT, Y., PACCHIONI, B., MILINO, C., LANFRANCHI, G., READMAN, J.W., MOORE, M.N., VIARENGO, A., JHA, A.N. 2017. Assessing the impact of benzo[a]pyrene on marine mussels: application of a novel targeted low density microarray complementing classical biomarker responses. PloS one 12, 0178460.

[80] DI, Y., AMINOT, Y., SCHROEDER, D.C., READMAN, J.W., JHA, A.N. 2017 Integrated biological responses and tissue-specific expression of p53 and ras genes in marine mussels following exposure to benzo $(\alpha)$ pyrene and C60 fullerenes, either alone or in combination. Mutagenesis 32, 77-90.

[81] LIU, F., CHUNG, S., OH, G., SEO, T.S. 2012. Three-dimensional graphene oxide nanostructure for fast and efficient water-soluble dye removal. ACS Applied Materials \& Interfaces 4, 922-927.

[82] SHARMA, P., DAS, M.R. 2013. Removal of a cationic dye from aqueous solution using graphene oxide nanosheets: investigation of adsorption parameters. Journal of Chemical \& Engineering Data 58, 151-158.

[83] ROBATI, D., MIRZA, B., RAJABI, M., MORADI, O., TYAGI, I., AGARWAL, S., GUPTA, V.K. 2016. Removal of hazardous dyes-BR 12 and methyl orange using graphene oxide as an adsorbent from aqueous phase. Chemical Engineering Journal 284, 687-697.

[84] WANG, J., CHEN, Z., CHEN, B. 2014. Adsorption of polycyclic aromatic hydrocarbons by graphene and graphene oxide nanosheets. Environmental Science \& Technology $\mathbf{4 8}, 4817-4825$.

[85] ZHANG, Y., CUI, W., AN, W., LIU, L., LIANG, Y., ZHU, Y. 2018. Combination of photoelectrocatalysis and adsorption for removal of bisphenol A over $\mathrm{TiO}_{2}$-graphene hydrogel with 3D network structure. Applied Catalysis B: Environmental 221, 36-46. 
[86] JANIK, P., ZAWISZA, B., TALIK, E., SITKO, R. 2018. Selective adsorption and determination of hexavalent chromium ions using graphene oxide modified with amino silanes. Microchimica Acta 185, 117.

[87] WEI, M., CHAI, H., CAO, Y., JIA, D. 2018. Sulfonated graphene oxide as an adsorbent for removal of $\mathrm{Pb} 2+$ and methylene blue. Journal of Colloid and Interface Science 524, 297-305.

[88] WU, L.K., WU, H., ZHANG, H.-B., CAO, H.-Z., HOU, G.Y., TANG, Y.P., ZHENG, G.Q. 2018. Graphene oxide/ $\mathrm{CuFe}_{2} \mathrm{O}_{4}$ foam as an efficient absorbent for arsenic removal from water. Chemical Engineering Journal 334, 1808-1819.

[89] NAM, S.W., JUNG, C., LI, H., YU, M., FLORA, J.R.V., BOATENG, L.K., HER, N., ZOH, K.D., YOON, Y. 2015. Adsorption characteristics of diclofenac and sulfamethoxazole to graphene oxide in aqueous solution. Chemosphere 136, 20-26.

[90] ZHU, K., SHANG, Y.Y., SUN, P.Z., LI, Z., LI, X.M., WEI, J.Q., WANG, K.L., WU, D.H., CAO, A.Y., ZHU, H.W. 2013. Oil spill cleanup from sea water by nanotubes sponges. Frontiers of Materials Science 7, 170-176.

[91] BAKIR, A., O'CONNOR, I.A., ROWLAND, S.J., HENDRIKS, A.J., THOMPSON, R.C. 2016. Relative importance of microplastics as a pathway for the transfer of hydrophobic organic chemicals to marine life. Environmental Pollution 219, 56-65.

[92] BESSELING, E., WEGNER, A., FOEKEMA, E.M., VAN DEN HEUVELGREVE, M.J., KOELMANS, A.A. 2013. Effects of microplastic on fitness and PCB bioaccumulation by the lugworm Arenicola marina (L.). Environmental Science \& Technology 47, 593-600.

[93] OLIVEIRA, M., RIBEIRO, A., HYLLAND, K., GUILHERMINO, L. 2013. Single and combined effects of microplastics and pyrene on juveniles (0+ group) of the common goby Pomatoschistus microps (Teleostei, Gobiidae). Ecological Indicators 34, 641-647.

[94] ROCHMAN, C.M., HOH, E., KUROBE, T., the, S.J. 2013. Ingested plastic transfers hazardous chemicals to fish and induces hepatic stress. Scientific Reports 3, 3263.

[95] AVIO, C.J., GORBI, S., MILAN, M., BENEDETTI, M., FATTORINI, D., D’ERRICO, G., PAULETTO, M., BARGELLONI, L., REGOLI, F. 2015. Pollutants bioavailability and toxicology risk from microplastics to marine mussels. Environmental Pollution 198, 211-222.

[96] BATEL, A., BORCHERT, F., REINWALD, H., ERDINGER, L., BRAUNBECK, T. 2018. Microplastic accumulation patterns and transfer of benzo[a] pyrene to adult zebrafish (Danio rerio) gills and zebrafish embryos. Environmental Pollution 235, 918-930.

[97] PAUL-PONT, I., LACROIX, C., FERNÁNDEZ, C.G., HÉGARET, H., LAMBERT, C., LE GOÏC, N., FRERE, L., CASSONE, A.L., SUSSARELLU, R., FABIOUX, C., GUYOMARCH, J., ALBENTOSA, M., HUVET, A., SOUDANT, P. 2016. Exposure of marine mussels Mytilus spp. to polystyrene microplastics: toxicity and influence on fluoranthene bioaccumulation. Environmental Pollution 216, 724-737. 
[98] GUILHERMINO, L., VIEIRA, L.R., RIBEIRO, D., TAVARES, A.S., CARDOSO, V., ALVES, A., ALMEIDA, J.M. 2018. Uptake and effects of the antimicrobial florfenicol, microplastics and their mixtures on freshwater exotic invasive bivalve Corbicula fluminea. Science of the Total Environment 622-623, 1131-1142.

[99] PITTURA, L., AVIO, C.G., GIULIANI, M.E., D'ERRICO, G., KEITER, S.H., CORMIER, B., GORBI, S., REGOLI, F. 2018. Microplastics as vehicles of environmental PAHs to marine organisms: combined chemical and physical hazards to the Mediterranean mussels, Mytilus galloprovincialis. Frontiers in Marine Science 5, 103.

[100] GONZALEZ-SOTO, N., HATFIELD, J., KATSUMITI, A., DUROUDIER, N., LACAVE, J.M., BILBAO, E., ORBEA, A., NAVARRO, E., CAJARAVILLE, M.P. 2019. Impacts of dietary exposure to different sized polystyrene microplastics alone and with sorbed benzo[a]pyrene on biomarkers and whole organism responses in mussels Mytilus galloprovincialis. Science of the Total Environment 684, 548-566.

[101] KATSUMITI, A., CAJAVILLE, M.P. 2019. Ecotoxicology of nanoparticles in aquatic systems. CRC Press: Boca Raton (1959-1998).

[102] BONCEL, S., KYZIOŁ-KOMOSIŃSKA, J., KRZYŻEWSKA, I., CZUPIOL, J. 2015. Interactions of carbon nanotubes with aqueous/aquatic media containing organic/inorganic contaminants and selected organisms of aquatic ecosystems - A review. Chemosphere 136, 211-221.

[103] SANCHÍS, J., OLMOS, M., VINCENT, P., FARRÉ, M., BARCELÓ, D. 2016. New Insights on the Influence of Organic Co-Contaminants on the Aquatic Toxicology of Carbon Nanomaterials. Environmental Science \& Technology 50, 961-969.

[104] VIARENGO, A., LOWE, D., BOLOGNESI, C., FABBRI, E., KOEHLER, A. 2007. The use of biomarkers in biomonitoring: a 2-tier approach assessing the level of pollutant-induced stress syndrome in sentinel organisms. Comparative Biochemistry and Physiology - Part C 146, 281-300.

[105] GOLDBERG, E.D. 1986. The Mussel Watch Concept. Environmental Monitoring and 51 Assessment, 7, 91-103.

[106] CAJARAVILLE, M.P., BEBIANNO, M.J., BLASCO, J., PORTE, C., SARASQUETE, C., VIARENGO, A. 2000. The use of biomarkers to assess the impact of pollution in coastal environments of the Iberian Peninsula: a practical approach. Science of the Total Environment 247, 295311 .

[107] GOLDBERG, E.D., KOIDE, M., HODGE, V., FLEGAL, A.R., MARTIN, J. 1983. U.S. Mussel Watch: 1977-1978 results on trace metals and radionuclides. Estuarine, Coastal and Shelf Science 16, 69-93.

[108] UNEP/RAMOGE. 1999. Manual on the biomarkers recommended for the MEDPOL Biomonitoring Programme.

[109] BROWNE, M.A., DISSANAYAKE, A., GALLOWAY, T.S., LOWE, D.M., THOMPSON, R.C. 2008. Ingested microscopic plastic translocates 
to the circulatory system of the mussel, Mytilus edulis (L.). Environmental Science \& Technology 42, 5026-5031.

[110] CANESI, L., CIACCI, C., FABBRI, R., MARCOMINI, A., POJANA, G., GALLO, G. 2012. Bivalve molluscs as a unique target group for nanoparticle toxicity. Marine Environmental Research 76,16-21.

[111] MATRANGA, V., CORSI, I. 2012. Toxic effects of engineered nanoparticles in the marine environment: model organism and molecular approaches. Marine Environmental Research 76, 32-40.

[112] ROCHA, T.L., GOMES, T., SOUSA, V.S., MESTRE, N.C., BEBIANNO, M.J. 2015. Ecotoxicological impact of engineered nanomaterials in bivalve molluscs: an overview. Marine Environmental Research 111, 74-88.

[113] CANESI, L., CORSI, I. 2016. Effects of nanomaterials on marine invertebrates. Science of the Total Environment 565, 933-940.

[114] GONZALEZ-SOTO, N., KATSUMITI, A., DUROUDIER, N., ORBEA, A., BILBAO, E., NAVARRO, E., CAJARAVILLE, M.P. 2018. Impact of microplastics alone or with adsorbed oil compounds from the water accommodated fraction of a North Sea crude oil on marine mussels Mytilus galloprovincialis. MICRO 2018 Fate and Impact of Microplastics: Knowledge, Actions and Solutions, Lanzarote 19-23 November.

[115] KOELMANS, A.A. 2015. Modeling the role of microplastics in bioaccumulation of organic chemicals to marine aquatic organisms. A critical review. In Marine Anthropogenic Litter (309-324). Springer: Berlin.

[116] MARTÍNEZ-ÁLVAREZ, I., LE MENACH, K., DEVIER, M.H., CAJARAVILLE, M.P., ORBEA, A., BUDZINSKI, H. 2018. Characterization of the adsorption/desorption of benzo(a)pyrene to/from polystyrene microand nanoplastics for further toxicity assessment. SETAC Europe $28^{\text {th }}$ Annual Meeting, Rome, 13-17 May.

[117] MARTÍNEZ-ÁLVAREZ, I., LE MENACH, K., DEVIER, M.H., CAJARAVILLE, M.P., ORBEA, A., BUDZINSKI, H. 2018. Assessment of the Trojan horse effect using PAH contaminated polystyrene microplastics: sorption studies and responses of adult zebrafish. MICRO 2018 Fate and Impact of Microplastics: Knowledge, Actions and Solutions, Lanzarote 19-23 November.

[118] KOLANDHASAMY, P., SU, L., LI, J., QU, X., JABEEN, K., SHI, H. 2018. Adherence of microplastics to soft tissue of mussels: A novel way to uptake microplastics beyond ingestion. Science of the Total Environment 610-611, 635-640.

[119] VAN CAUWENBERGHE, L., CLAESSENS, M., VANDEGEHUCHTE, M.B., JANSSEN, C.R. 2015. Microplastics are taken up by mussels (Mytilus edulis) and lugworms (Arenicola marina) living in natural habitats. Environmental Pollution 199, 10-17.

[120] QU, X., SU, L., LI, H., LIANG, M., SHI, H. 2018. Assessing the relationship between the abundance and properties of microplastics in water and in mussels. Science of the Total Environment 621, 679-686. 
Karbonoan oinarritutako nanomaterialen eta mikro eta nanoplastikoen eragina

kutsatzaile organiko iraunkorren garraiatzaile gisa organismo itsastarretan

[121] LI, J., LUSHER, A.L., ROTCHELL, J.M., DEUDERO, S., TURRA, A., BRATE, I.L.N., SUN, C., HOSSAIN, M.S., LI, Q., KOLANDHASAMY, P., SHI, H. 2019. Using mussel as a global bioindicator of coastal microplastic pollution. Environmental Pollution 244, 522-533.

[122] MAGNI, S., GAGNÉ, F., ANDRÉ, C., DELLA TORRE, C., AUCLAIR, J., HANANA, H., PARENTI, C.C., BONASORO, F., BINELLI, A. 2018. Evaluation of uptake and chronic toxicity of virgin polystyrene microbeads in freshwater zebra mussel Dreissena polymorpha (Mollusca: Bivalvia). Science of the Total Environment 631-632, 778-788.

[123] BRATE, I.L., BLAZQUEZ, M., BROOKS, S.J., THOMAS, K.V. 2018. Weathering impacts the uptake of polyethylene microparticles from toothpaste in Mediterranean mussels (M. galloprovincialis). Science of the Total Environment 626, 1310-1318.

[124] BROWNE, M.A., NIVEN, S.J., GALLOWAY, T.S., ROWLAND, S.J., THOMPSON, R.C. 2013. Microplastic moves pollutants and additives to worms, reducing functions linked to health and biodiversity. Current Biology 23, 2388-2392.

[125] DÉTRÉE, C., GALlardo-ESCÁRATE, C. 2017. Polyethylene microbeads induce transcriptional responses with tissue-dependent patterns in the mussel Mytilus galloprovincialis. Journal of Molluscan Studies 83, 220225.

[126] SANTANA, M.F., MOREIRA, F.T., PEREIRA, C.D., ABESSA, D.M., TURRA, A. 2018. Continuous exposure to microplastics does not cause physiological effects in the cultivated mussel Perna perna. Archives of Environmental Contamination and Toxicology 74, 594-604.

[127] RIBEIRO, F., GARCIA, A.R., PEREIRA, B.P., FONSECA, M., NÉLIA, C., MESTRE, N.C., FONSECA, T.G., LAURA, M., ILHARCO, L.M., BEBIANNO, M.J. 2017. Microplastics effects in Scrobicularia plana. Marine Pollution Bulletin 122, 379-391.

[128] BRANDTS, I., TELES, M., GONÇALVES, A.P., BARRETO, A., FRANCO-MARTINEZ, L., TVARIJONAVICIUTE, A., MARTINS, M.A., SOARES, A.M.V.M., TORT, L., OLIVEIRA, M. 2018. Effects of nanoplastics on Mytilus galloprovincialis after individual and combined exposure with carbamazepine. Science of the Total Environment 643, 775-784.

[129] CAJARAVILLE, M.P., DÍEZ, G., MARIGÓMEZ, I., ANGULO, E. 1990. Responses of the basophilic cells of the digestive gland of mussels to petroleum hydrocarbon exposure. Diseases of Aquatic Organisms 9, 221-228.

[130] ZORITA, I., ORTIZ-ZARRAGOITIA, M., SOTO, M. CAJARAVILLE, M.P. 2006. Biomarkers in mussels from a copper site gradient (Visnes, Norway): an integrated biochemical, histochemical and histological study. Aquatic Toxicology 78, 109-116.

[131] GARMENDIA, L., SOTO, M., VICARIO, U., KIM, Y., CAJARAVILLE, M.P., MARIGÓMEZ, I. 2011. Application of a battery of biomarkers in mussel digestive gland to assess long-term effects of the Prestige oil spill in 
Galicia and Bay of Biscay: tissue-level biomarkers and histopathology. Journal of Environmental Monitoring 13,915-932.

[132] BIGNELL, J., CAJARAVILLE, M.P., MARIGÓMEZ, I. 2012. Background document: histopathology of mussels (Mytilus spp.) for health assessment in biological effects monitoring. Integrated monitoring of chemicals and their effects. In: Davies, I.M., Vethaak, A.D. (Eds.), ICES Cooperative Research Report N. 315, Copenhagen, Denmark, 111-120.

[133] CAJARAVILle, M.P., MARIGÓMEZ, J.A., DIEZ, G., ANGUlO, E. 1992. Comparative effects of the water accommodated fraction of three oils on mussels-2. Quantitative alterations in the structure of the digestive tubules. Comparative Biochemistry and Physiology - Part C 102, 113-123.

[134] WELDEN, N.A., COWIE, P.R. 2016. Long-term microplastic retention causes reduced body condition in the langoustine, Nephrops norvegicus. Environmental Pollution 218, 895-900.

[135] SUSSARELLU, R., SUQUET, M., THOMAS, Y., LAMBERT, C., FABIOUX, C., PERNET, M.E.J., CORPOREAU, C. 2016. Oyster reproduction is affected by exposure to polystyrene microplastics. Proceedings of the National Academy of Sciences 113, 2430-2435.

[136] XU, X.Y., LEE, W.T., CHAN, A.K.Y., LO, H.S., SHIN, P.K.S., CHEUNG, S.G. 2017. Microplastic ingestion reduces energy intake in the clam Atactodea striata. Marine Pollution Bulletin 24, 798-802.

[137] GREEN, D.S., BOOTS, B., O'CONNOR, N.E., THOMPSON, R. 2017. Microplastics affect the ecological functioning of an important biogenic habitat. Environmental Science \& Technology 51, 68-77.

[138] DE SÁ, L.C., OLIVERA, M., RIBEIRO, F., ROCHA, T.L., FUTTER, M.N. 2018. Studies of the effects of microplastics on aquatic organisms: What do weknow and where should we focus our efforts in the future? Science of Total Environment 645, 1029-1039. 